\title{
Estudio experimental sobre la utilización de células madre humanas en la terapia de los defectos periodontales: resultados preliminares
}

\author{
Experimental study on the use of human stem cell therapy in periodontal \\ defects: Preliminary results
}

\author{
CARINI F* \\ MENCHINI FABRIS GB** \\ BIAGI E*** \\ SALVADE' A*** \\ SBORDONE $\mathbf{L} * * * *$ \\ BALDONI MG *****
}

\begin{abstract}
Carini F, Menchini Fabris GB, Biagi E, Salvade' A, Sbordone L, Baldoni MG. Estudio experimental sobre la utilización de células madre humanas en la terapia de los defectos periodontales: resultados preliminares. Av Periodon Implantol. 2011;23, 2: 97-107.
\end{abstract}

\section{RESUMEN}

La destrucción del ligamento periodontal y de la cresta alveolar causada por la enfermedad periodontal, constituye la principal causa de pérdida dentaria en pacientes adultos.

Resulta difícil que la terapia en la enfermedad periodontal avanzada lleve a una restitutio ad integrum de la estructura que se ha perdido por la imposibilidad de regenerar la correcta anatomía del sistema perdido. Este estudio tiene como objetivo evaluar el potencial y la estabilidad de la utilización de células madre mesenquimales (MSC) en la regeneración periodontal de la estructura original. Su objetivo es determinar un método de regeneración de la estructura periodontal original que se ha perdido después de la enfermedad periodontal, cerca de los elementos dentales vitales sin patologías correlacionadas. Este estudio constituye una experimentación de fase 1 aprobada por el Instituto Superior de Salud sobre un número limitado de pacientes, cuyo objetivo principal será la evaluación de la biocompatibilidad y toxicidad in vivo de las células madre mesenquimales diferenciadas en sentido osteoblástico, sostenidas por andamios de colágeno biomiméticos en pacientes afectados por periodontopatía severa. El protocolo describe el transplante de células madre mesenquimales derivadas de muestras de un aspirado percutáneo de médula ósea.

Las células de la médula ósea son manipuladas ex vivo para el aislamiento de la población de células madre mesenquimales.

Las células madre adultas son diferenciadas en las líneas celulares que forman el sistema periodontal, sucesivamente inducidas y cultivadas en andamios adecuados definidos en base a características propias con el fin de obtener una distribución uniforme de las líneas celulares, e injertadas en el sitio receptor estimulado adecuadamente hasta la degradación de los andamios, en un tiempo suficiente para garantizar la estabilidad de las diferentes líneas celulares y la recíproca interacción, con el fin de recrear la correcta anatomía estructural del periodonto perdido.

Después de una fase de expansión celular, estas células se introducen en una estructura biomimética (andamios en colágeno), y se inducen a la diferenciación en sentido osteogénico.

El producto final que consta de andamios y células mesenquimales diferenciadas en sentido osteoblástico, se instala por último en el defecto alveolar periodontal.

La experimentación se basa en la posibilidad de utilizar células madre mesenquimales autólogas a partir de la médula ósea humana.

\footnotetext{
* Profesor agregado de la Universidad de Milán-Bicocca. Jefe de Cirugía. Clínica Dental Hospital San Gerardo, Monza. ** Cirugía oral. Universidad de Milán-Bicocca. Asistente de Investigación. Departamento de Cirugía. Universidad de Pisa. *** Laboratorio de Terapia Celular "Stefano Verri". Centro de Investigación "M. Tettamanti". Hospital San Gerardo, Monza

**** Profesor de la Universidad de Pisa, Director UO de Odontología y Implantologíaa, Gestión Hospitalaria-Universitaria Pisana, Pisa.

***** Profesor. Director de la Escuela de Cirugía Bucal. Universidad de Milán-Bicocca. Director UO de Odontología. Clínica Dental. Hospital San Gerardo, Monza.
} 
La finalidad es la de estimular la regeneración de PDL cerca de la pared radicular y la formación de hueso nuevo sobre el PDL, beneficiándose de las técnicas de regeneración-reconstrucción ósea, de manera que se recree la correcta anatomía periodontal.

Los resultados presentados en este trabajo conciernen el primer paciente tratado con esta metodología y afectarán los estudios siguientes para la prueba con una cobertura más amplia.

PALABRAS CLAVE: Células madre en periodoncia, regeneración periodontal guiada, terapia periodontal.

\section{SUIMIMARY}

Destruction of periodontal ligament and alveolar ridge rerorption caused by periodontal disease is the leading cause of tooth loss in adults.

Therapy of advanced periodontal disease leads for a total recovery of the structure lost by the inability to regenerate the pristine correct anatomy system.

The aim of this study is to assess the potential use of mesenchymal stem cells (MSCs) in the regeneration of original periodontal structure.

This study is an experimental phase 1 approved by the Italian Institute of Health on a limited number of patients; main objective will be to assess the biocompatibility and toxicity in vivo of differentiated mesenchymal stem cells into osteoblast sense, supported by biomimetic collagen scaffolds in patients with severe periodontal disease.

The protocol describes transplantation of mesenchymal stem cells derived from samples of percutaneous bone marrow aspirate.

The bone marrow cells are manipulated ex vivo to isolate mesenchymal stem cell population.

After a phase of cell expansion, these cells are induced to differentiate into periodontal system cell lines in a biomimetic structure (collagen scaffold). Induction and culturation in an appropriate scaffold defined on specific characteristics lead to obtain an uniform distribution of cell lines. After 28 days Scs are grafted into the defect site of the patient.

Scaffold degradation time will ensure stability of the different cell lines and reciprocal interaction, in order to recreate the correct structural anatomy of periodontium lost.

The purpose is to stimulate the regeneration of PDL near the root wall and new bone formation on the PDL, benefiting from the techniques of bone regeneration, reconstruction, as to recreate the pristine periodontal anatomy.

The results presented in this paper concern the first patient treated with this method and will affect following studies for test for a wider coverage.

KEY WORDS: Periodontal stem cells; guided tissue regeneration, periodontal therapy.

Fecha de recepción: 15 de noviembre de 2009.

Fecha de aceptación: 7 de enero de 2010.

\section{INTRODUCCIÓN}

Los efectos de la enfermedad periodontal (PD) se manifiestan como la destrucción del periodonto, sistema que se compone de encía, cemento radicular, ligamento periodontal (PDL) y hueso alveolar, y son la consecuencia principal de la pérdida de dientes en los adultos.

El PDL es un tejido conectivo fibroso localizado entre el cemento radicular y la superficie cortical interna de los alveolos dentarios.
La reparación del periodonto y la regeneración de los tejidos periodontales constituyen los objetivos principales del tratamiento de las PD.

La reparación periodontal completa comporta una nueva cementogénesis, osteogénesis y formación de fibras del ligamento periodontal (1).

Las estrategias actuales se basan en terapias causales a través de la eliminación de los agentes infecciosos presentes en el periodonto y la consiguiente regene- 
ración por medio de técnicas de regeneración guiada de tejidos (GTR) con o sin la posibilidad de injertos óseos (BG) y el uso de factores de crecimiento (GF). Sin embargo, con estas técnicas no se obtiene el periodonto original (2).

Los resultados histológicos obtenidos muestran una regeneración alterada y la presencia de tejidos similares a los perdidos pero con características diferentes, y en la mayoría de los casos con la infructuosa regeneración del ligamento periodontal entre los tejidos neoformados de cemento y de hueso, determinando desde el punto de vista histológico una conexión directa, evaluada clínicamente como una anquilosis entre la porción de los tejidos neoformados (3).

Por eso la necesidad de inducir la regeneración del sistema periodontal en su totalidad, permitiendo también a las células del ligamento periodontal desarrollarse y al mismo tiempo a los otros tejidos obtener un sistema periodontal organizado y completo $(4,1)$

Por medio de células madre adultas (ASC), se han propuesto diferentes técnicas de Ingeniería de tejidos para obtener una completa, predecible y reproducible regeneración del periodonto. Las células madre mesenquimales (MSC) han sido identificadas por primera vez en aspirados de sangre de médula ósea de un adulto (5) gracias a su capacidad para formar organizaciones clonogénicas de células adherentes fibroblásticas o de unidades fibroblásticas organizadas en colonias con potencial de someterse a proliferaciones in vitro y diferenciarse en distintas líneas celulares estromales $(6,7)$.

Actualmente la investigación científica está orientada al uso de MSC que provienen del aspirado de médula ósea (BMSC) (8-12).

Zhao et al. (12) cree que el uso del aspirado medular es mejor en cuanto tiene una mayor homogeneidad celular, esto permite un mejor reconocimiento de las células que podrían estimular la regeneración, característica que asociada a una maduración, favorecería la posibilidad de inducción de la regeneración.

Otros autores prefieren la línea derivada de células del PDL (PDLSC) de III molares (13-18).

Seo et al. (13) sostiene que la capacidad de formar colonias de fibroblastos de las PDLSC es 12 veces mayor que la de las BMSC (170 por PDLSC y 14 por BMSC por 105 células/placa). Algunos autores señalan la excesiva heterogeneidad de la población celular del PDL, advirtiendo la necesidad de identificar la correcta subpoblación implicada en los procesos reparativos/ regenerativos del PDL $(13,17,19)$.

Las MSC, en efecto, presentan múltiples ventajas, por ejemplo fácil aislamiento, cultivo y estabilidad fenotípica in vitro (20), demostrada capacidad de diferenciación (21) y además, importantes propiedades inmunomoduladoras utilizadas de manera alogénica.

Esta técnica consiste en un implante de un andamio (biomaterial poroso) cargado con células apropiadas para inducir la regeneración del tejido. Tales estructuras han sido implantadas en modelos de animales, obteniendo resultados prometedores por lo que respecta a la formación de tejido óseo oral $(22,23)$. Estos estudios, que presentan diferencias en la especie animal empleada, en el defecto óseo creado y en la naturaleza del andamio muestran, sin embargo una ventaja significativa en la curación de los defectos óseos, demostrando una buena fijación celular y una participación directa de las células MSC inoculadas en la formación del nuevo tejido.

\section{MATERIALES Y MÉTODOS}

El estudio forma parte de una experimentación aprobada por el Ministerio de Salud italiano por lo cual sigue el protocolo de fase 1 autorizado por el Instituto Superior de Sanidad, para el tratamiento piloto de 7 pacientes. La duración total será de 48 meses.

Los pacientes han sido informados verbalmente sobre la intervención, han completado un módulo específico para explicar la finalidad del estudio y su participación, además del consenso dado en relación a la operación quirúrgica.

Los pacientes debían presentar periodontitis crónica severa con valor de PPD inferior a $8 \mathrm{~mm}$ en al menos 2 sitios. En la proximidad de cada sitio había una banda de encía adherida suficiente para la manipulación quirúrgica de los bordes y para el anclaje de suturas. Los pacientes debían presentar una historia clínica y radiográfica completa.

Han sido excluidos de la experimentación sujetos que presentaban patologías sistémicas, condiciones alteradas de salud, mujeres embarazadas o en lactancia, fumadores (>10 cigarrillos x día). Además, se han ex- 
cluido los pacientes con "puntuación de la placa dental completa" (FMPS) y "puntuación de sangrado bucal completo" (FMBS) $>20 \%$ después de la fase de terapia etiológica, que incluía motivación e instrucción de higiene oral, sesiones de raspaje y alisado radicular.

Durante la terapia causal se ha verificado y corregido la presencia de trauma oclusal. Los elementos dentales con movilidad han sido estabilizados con ferulización en los dientes adyacentes por medio de ferulizaciones adhesivas extracoronales.

Tres meses después de finalizar la terapia causal, se ha procedido a la evaluación de los valores basales (FMPS, FMBS, PPD, CAL) por el mismo operador mediante una sonda periodontal (CP-15UNC Hu-Freidy, EEUU) y radiografías intraorales de los sitios de interés.

Todas las cirugías y controles han sido efectuadas en el Servicio de Odontoestomatología (Hospital San Gerardo, Monza, Italia).

El primer paciente tratado es un varón de 40 años de raza caucásica con periodontitis crónica. Haciendo el examen radiográfico mediante OPT (Fig. 1) y (sistemático) intraoral, se han observado diferentes defectos óseos en particular por lo que respecta al segundo molar derecho y al segundo premolar inferior derecho.

El examen clínico confirmaba la presencia de los defectos periodontales con valor de PPD de $8 \mathrm{~mm}$ en relación con las superficies distales del elemento 1.7 que también tuvo una furcación de grado II (Fig. 2) y un valor de PPD, de $7 \mathrm{~mm}$ en la superficie distal de 4,5 (Fig. 3).

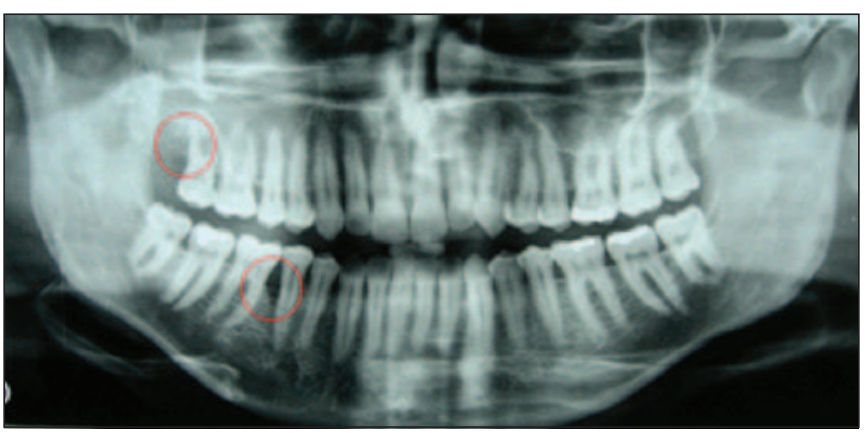

Fig. 1: $R X$ preoperatoria.

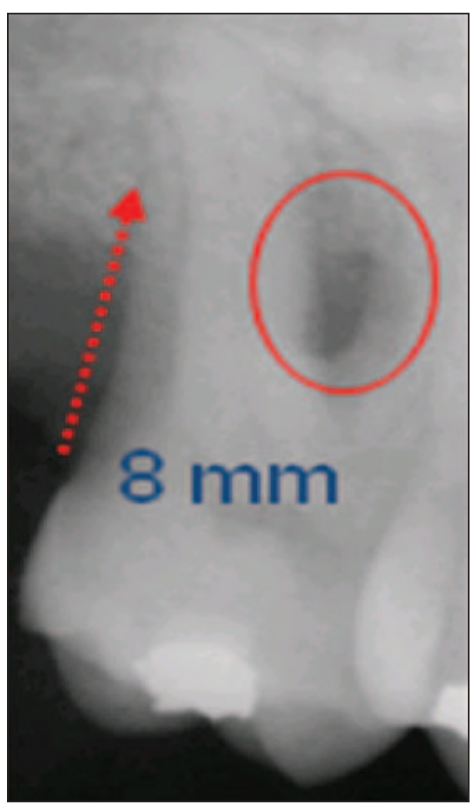

Fig. 2: 1.7 Déficit periodontal preoperatorio.
Fig. 3: 4.5 Déficit periodontal preopera-

torio.

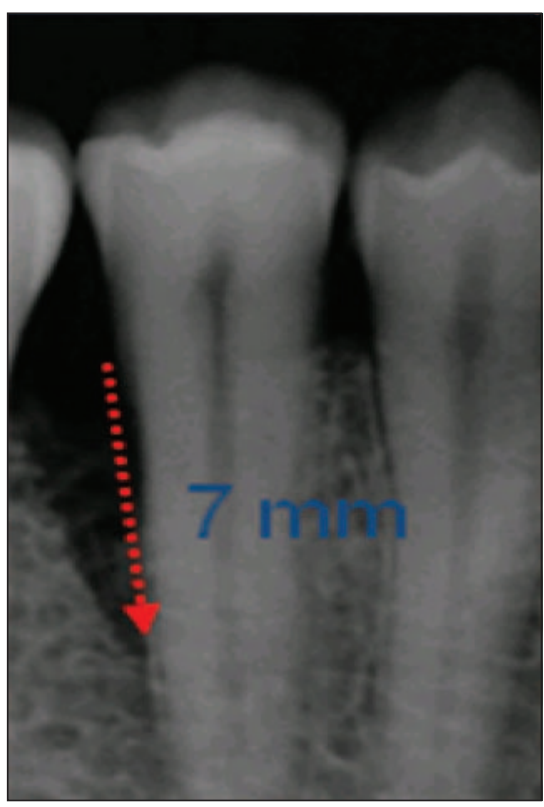

\section{Extracción de células madre}

Las células madre (MCS) se han obtenido mediante la extracción de $15 \mathrm{ml}$ de la médula ósea de la cresta ilíaca del paciente. El material se ha puesto en bolsas de transporte y se ha enviado al laboratorio para la fase de expansión celular.

Todos estos procedimientos se han desarrollado en un laboratorio de terapia celular y génica (Cell Therapy 
Laboratory, "Stefano Verri", Monza, Italia) en condiciones de GMP (Good Manifacturing practice).

\section{Aislamiento, expansión y diferenciación de las MSC sobre andamio}

El procedimiento, ha sido descrito anteriormente en un trabajo por el mismo grupo de estudio $(24,25)$.

Las células se mantienen en cultivo hasta que se logre un número adecuado de células sobre la base del defecto óseo de cada paciente.

Una parte alícuota de células será utilizada para la caracterización fenotípica, mientras otra alícuota será empleada para las pruebas microbiológicas (endotoxina, micoplasma, bacterias aerobias y anaerobias).

La instalación de una estructura biomimética representa una técnica conocida, cuya biocompatibilidad ha sido ya evaluada.

El colágeno utilizado como estructura para el andamio ( $₫$ di Gingistat - VEBAS) ya está en venta para uso clínico y quirúrgico (26).

Las células se ponen en el andamio Gingistat en una concentración de $1 \times 106 \mathrm{MSC} / 125 \mathrm{~mm}^{3}$ andamio y, 3 días después, se inducen a la diferenciación en sentido osteogénico mediante un dispositivo osteogénico clinical-grade, que consiste en DMEM GMP-grade, 10\% FBS Hyclone, antibióticos GMP-grade, L-glutamina GMP-grade con la añadidura de factores diferenciados $100 \mathrm{nM}$ dexametasona, $0.05 \mathrm{mM}$ vitamina C, y 10 $\mathrm{mM}$ sodio glicerofosfato (Farve).

Paralelamente a los andamios, se realizarán placas de una alícuota celular de control también en cubetas de cultivo y se inducirá a la diferenciación con dispositivo osteogénico clinical-grade, con el fin de realizar las evaluaciones oportunas de diferenciación osteoblástica.

A partir del día 21, y no más allá del día 42, con plazo semanal, será efectuada la coloración Alizarin Red en las cubetas de cultivo de control para observar el comienzo del proceso de mineralización que coincide con la positividad inicial aparecida del colorante Alizarin Red. El día en que se observe el inicio de coloración en la placa, se congelará y analizará un andamio, para tener una evaluación más correcta y adecuada del grado de diferenciación del material biodegradable empleado para la inoculación en el paciente.
Si el producto resulta idóneo, o sea si ha empezado el proceso de diferenciación en sentido osteogénico, se informa al médico odontólogo y se programa la intervención quirúrgica en un tiempo de 1-3 días, mientras tanto se efectuarán los controles microbiológicos adecuados (endotoxina, micoplasma, cultivos aerobios y anaerobios).

El dato que se refiere a la negatividad de endotoxina será el único disponible para la liberación del lote celular para uso clínico. Los datos del examen del cultivo del micoplasma y de bacterias/hongos aerobiosanaerobios, se conocerán sólo después de la inoculación (debido a la necesidad de utilizar el producto fresco y la imposibilidad de realizar cualquier procedimiento de conservación en frío o por congelación).

El número de células mesenquimales (un millón de células por $125 \mathrm{~mm}^{3}$ de andamio) ha sido seleccionado sobre la base de los datos indicados en literatura en protocolos análogos de regeneración ósea en modelos preclínicos $(27,28)$.

El número de andamios (o sea, de células madre mesenquimales) producido para cada paciente, podrá cambiar en relación a los defectos óseos y el número de lesiones de cada paciente (Fig. 4).

\section{Intervención quirúrgica}

Se ha realizado con anestesia locorregional, por medio de infiltraciones de lidocaína y adrenalina 1:50000. Antes de empezar el tratamiento los pacientes han

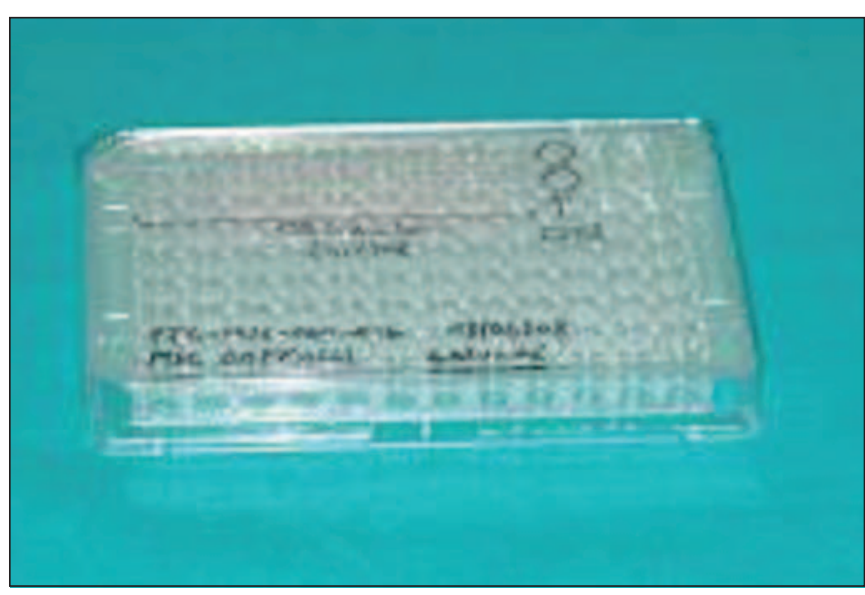

Fig. 4: Trasporte Scaffold con MSCs. 
efectuado enjuagues por $2 \mathrm{~min}$. con Clorhexidina $0,12 \%$ (Corsodyl).

El acceso quirúrgico se realiza con una incisión intrasulcular que incluye por lo menos cuatro elementos dentales en proximidad del elemento dental relacionado con el defecto periodontal. Esto permite la instalación de un borde (muco periostio) sin tracción en la ladera lingual y vestibular.

Se ha procedido a la eliminación de todo el tejido de granulación presente en el pulido de la superficie radicular expuesta y a su condicionamiento mecánico por medio de instrumentos manuales y ultrasónicos (Fig.5).

Se ha efectuado la sutura preliminar de los bordes de la piel por medio de puntos colchoneros verticales no cerrados.

El defecto periodontal ha sido llenado por la introducción del andamio que contiene las células madre cultivadas (Figs. 6 y 7), compactándolas en más estratos hasta la finalización del defecto por medio de un obturador estéril. Se ha concluido este trabajo cerrando los puntos de sutura reposicionando el borde hasta la unión cemento adamantino.

\section{Fase posquirúrgica}

Para el control del dolor y del edema se ha suministrado un analgésico y antiinflamatorio a base de Nimesulide, una dosis de $100 \mathrm{mg}$ al final de la intervención, y otra 8 horas después. El fármaco se ha ad-

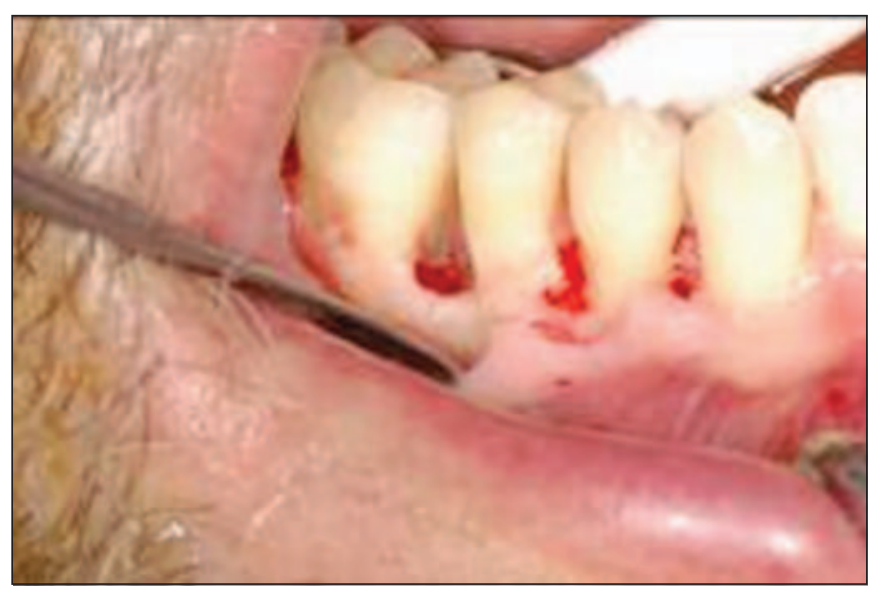

Fig. 5: Fase quirúrgica.

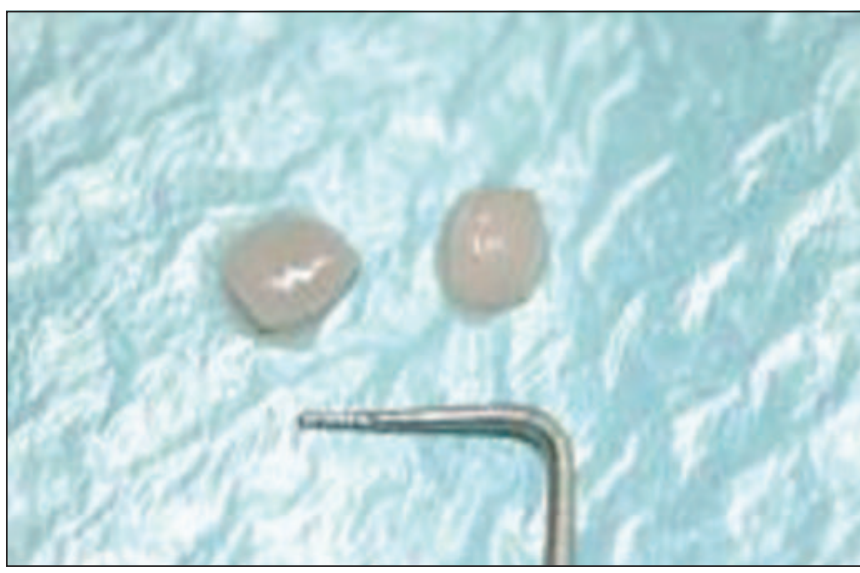

Fig. 6: Scaffold con MSCs.

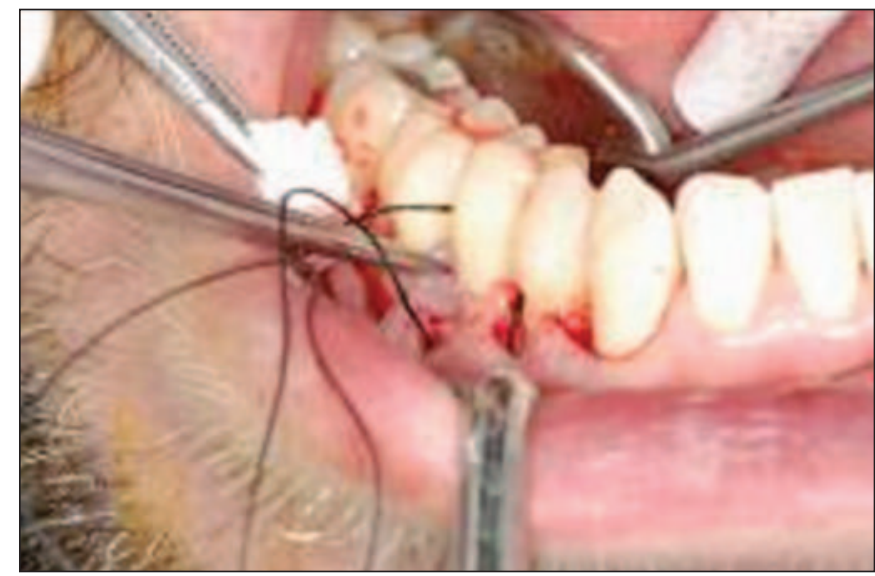

Fig. 7: Injerto Scaffold y MSCs.

ministrado según necesidad por 5 días, máximo dos veces al día.

Al comienzo de la intervención quirúrgica se han suministrado 2 gramos de amoxicilina y ácido clavulánico (augmentin l gr), sucesivamente la terapia ha continuado con suministraciones de 1 gr cada 12 horas por 6 días.

Se ha explicado al paciente la necesidad de controlar la placa en las respectivas zonas durante las primeras 2 semanas por medio de enjuagues con clorhexidina de $0,12 \%$ por 2 minutos dos veces al día.

Las suturas se han eliminado después de 9 días, y se han programado controles semanales para las primeras 4 semanas durante las cuales se ha controlado el 
proceso de curación y se ha eliminado la placa bacteriana de la zona quirúrgica.

Al final de las 4 semanas el paciente se ha sometido a sesiones de higiene oral profesional.

\section{RESULTADOS}

No se han verificado complicaciones durante el período de curación.

Seis meses después de la intervención quirúrgica se han observado FMPS, FMBS, PPD y CAL y se ha realizado una radiografía intraoral (con técnica de cono largo y centrador de Rinn) (Figs. 8, 9 y 10).

Los indicadores de placa y sangrado se han mantenido en $<20 \%$.

A nivel distal del elemento 1.7 se registra un valor de PPD de $4 \mathrm{~mm}$ y una reducción de las furcaciones de primer grado. En el nivel distal del elemento $4.5 \mathrm{se}$ registra un valor de PPD de $3 \mathrm{~mm}$, indicando un mejoramiento en ambos defectos en relación al valor inicial.

En ninguno de los dos sitios se ha observado recesión gingival cerca de los elementos afectados en la instalación de los bordes quirúrgicos.

En la radiografía se ha observado un relleno del área cerca de los defectos periodontales preoperatorios.

\section{DISCUSIÓN}

El tratamiento de la enfermedad periodontal se divide en dos fases distintas: el control de la infección periodontal, y la regeneración del sistema periodontal perdido. Por lo que concierne el tratamiento de los defectos periodontales, se habla de terapia regenerativa refiriéndose a los procedimientos adecuados para obtener la sustitución/reconstitución de los tejidos periodontales perdidos. La regeneración periodontal se define por lo tanto, como la reparación de los tejidos de soporte perdidos e incluye hueso alveolar, nuevo cemento y nuevo ligamento periodontal. Hasta hoy, entre los enfoques terapéuticos que han sido propuestos para la regeneración del hueso en defectos periodontales graves, todavía no hay procedimientos adecuados para asegurar un resultado perfectamente previsible y reproducible.

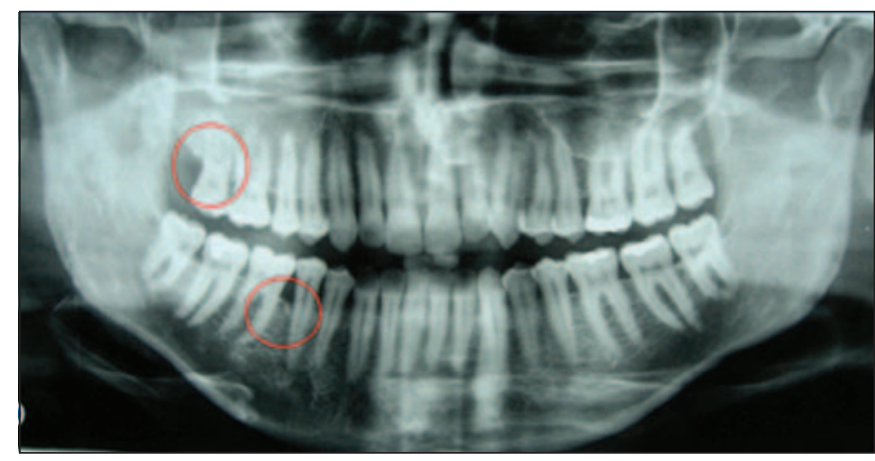

Fig. 8: $R X 6$ mes postoperatorio.

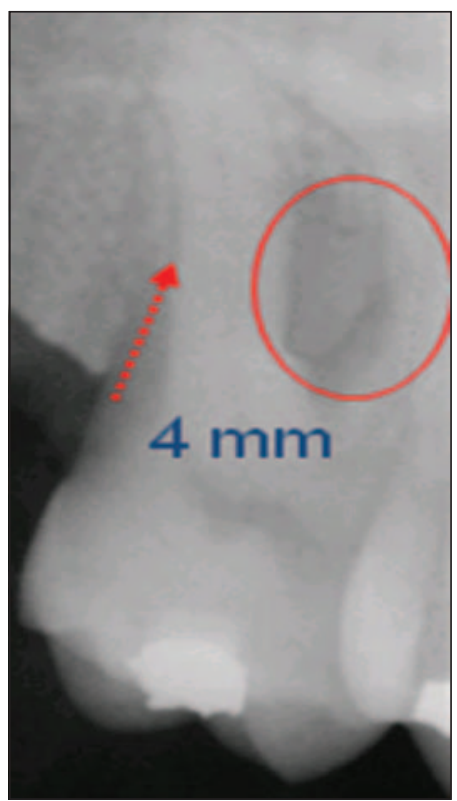

Fig. 9: 1.76 mes postoperatorio.
Fig. 10: 4.56 mes postoperatorio.

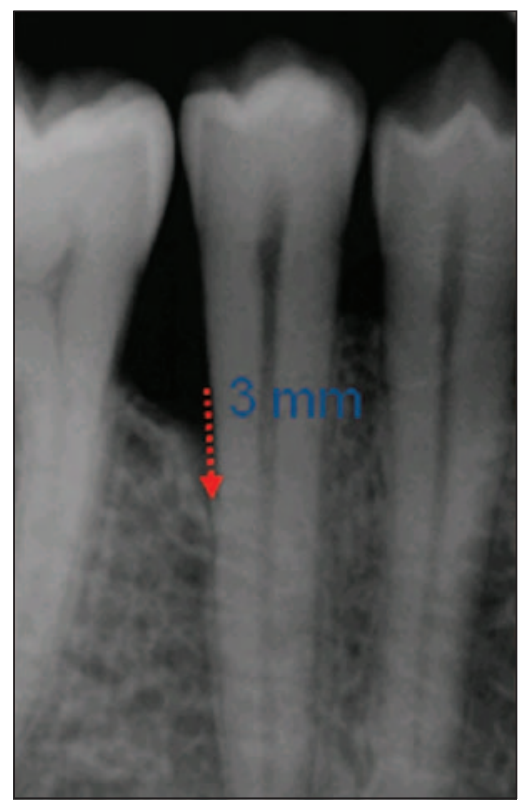


El tratamiento de los defectos infraóseos representa un gran desafío para los clínicos. Por medio de procedimientos de raspado y alisado radicular se obtiene un temporáneo "estado de salud" del sistema periodontal, pero sólo con la fase quirúrgica de modelado de deformaciones óseas, inducidas por la enfermedad periodontal a través de una terapia de resección y modelado óseo o una terapia regenerativa o reconstructiva mediante la aplicación de membranas, agentes biológicos o injerto de biomateriales (29).

No obstante algunos autores definen la curación obtenida como "regeneración periodontal", en varios estudios clínicos e histológicos en el hombre $(27,30)$, en la actualidad es todavía incierto un restablecimiento completo y previsible de los tejidos periodontales. Aunque su eficacia está demostrada, existe una sustancial variabilidad en la respuesta clínica, que puede ser atribuida sólo en parte a los diferentes biomateriales o agentes biológicos utilizados (30).

Varios autores sostienen que todos los tratamientos reconstructivos producen resultados comparables o más favorables respecto a los procedimientos convencionales de desbridamiento con colgajo abierto (OFD), por lo que concierne los parámetros de curación de tejidos duros y blandos (mejoramiento del ataque clínico, reducción de la profundidad de los sacos y relleno óseo) $(27,31)$.

La excesiva heterogeneidad de los estudios crea todavía notables desacuerdos sobre el papel que cumple el material de injerto.

Esto reduce la posibilidad de llegar a conclusiones generales sobre la previsión de técnicas como la Regeneración Tisular Guiada (RTG) o como los procedimientos de injerto y la aplicación de proteínas de la matriz del esmalte para el tratamiento de los defectos infraóseos.

A causa del número limitado de estudios actualmente disponible, no se puede llegar a conclusiones definitivas por lo que respecta a las causas de heterogeneidad en los resultados. Se requieren ulteriores investigaciones para identificar factores como los criterios de selección de los pacientes, de los sitios a tratar, la selección de materiales y de técnicas potencialmente asociadas con un resultado favorable a la terapia de estos defectos periodontales. En la comparación de los resultados clínicos de los diferentes procedimientos, se debe tener en cuenta que el mejoramiento de los parámetros clínicos no implica necesariamente el mismo tipo de curación a nivel histológico.

Mientras que con algunos procedimientos reconstructivos como la RTG y la aplicación de proteínas de la matriz del esmalte, se ha demostrado histológicamente una "real" y total regeneración periodontal, con el injerto de algunos biomateriales hay todavía un profundo debate sobre la causa de mejoramientos clínicos, o sea, el restablecimiento total de tejidos perdidos (incluso hueso, cemento y ligamento periodontal) o un simple relleno de los defectos óseos presentes.

La reparación de defectos óseos mediante un protocolo RTG está clínicamente difundida pero tiene problemas relacionados a la variabilidad de los resultados, el limitado mejoramiento clínico y la susceptibilidad a las infecciones (32).

Por lo tanto son necesarios nuevos métodos que permitan obtener resultados clínicos más reproducibles.

La ingeniería de tejidos es el campo más innovada por lo que respecta a los estudios de medicina regenerativa.

Hay muchos trabajos en la literatura científica sobre el posible uso de células madre mesenquimales en la ingeniería de tejidos, especialmente sobre la regeneración ósea (23).

La técnica prevé el uso de células madre dentro de una estructura de material poroso, llamada andamio, que pueda guiarlas en el defecto manteniéndolas en un soporte adecuado para el crecimiento y la diferenciación.

La selección de las características del andamio constituye todavía un debate abierto, también para las células, se han propuesto diferentes posibilidades de tratamiento.

Esta técnica prevé la instalación del andamio cargado con células adecuadas para inducir la regeneración del tejido elegido.

Estas estructuras han sido instaladas en modelos de animales, y recientemente en humanos, obteniendo así resultados prometedores en relación a la formación de tejido óseo (33).

La utilización de estas técnicas en humanos constituye todavía una fase inicial y no hay muchos estudios en la literatura científica. 
En este trabajo el material de experimentación tiene una forma que permite el posicionamiento en el defecto periodontal e impide la sucesiva (dehiscencia/ exposición) de tejidos gingivales reposicionados.

La condición fundamental es que el material actúe de manera conforme a los principios guía para la regeneración: la arquitectura interna del andamio debía acelerar la colonización del fenotipo celular deseado e inducir el crecimiento de tejido compatible con el tejido a regenerar; además debe impedir el crecimiento de tejido no deseado.

En la regeneración de tejidos mediante productos bioingenierizados parece haber una estrecha correlación entre el tamaño del poro y la estructura de soporte tridimensional (andamio), y el tamaño de las células que serán instaladas y las que se formarán a partir de los procesos de regeneración. La estructura del material tiene que ser biodegradable para permitir la gradual pero total sustitución del tejido regenerado.

El uso de estas técnicas en humanos constituye todavía una fase inicial, pero los trabajos muestran la importancia de la expansión ex vivo de MSC autólogas de médula ósea para reducir la invasividad de la técnica, y la necesidad de un soporte poroso sobre el cual se pueda desarrollar el tejido de nueva formación (34-35).

En ningún trabajo, en los que se han utilizado MSC autólogas, se han observado reacciones inmunitarias o efectos colaterales sistémicos (33).

\section{CONCLUSIONES}

Con este estudio preliminar hemos evaluado la eficacia de un protocolo terapéutico, sobre el cual no existen todavía estudios en literatura científica, como preliminar a un trabajo siguiente para completar esta experimentación y para otras futuras que puedan permitir un número más amplio de pacientes, y una rigidez experimental diferente por medio de variables de doble ciclo y técnicas split-mouth (boca partida).

El valor de este trabajo se basa en la demostración de su aplicación, de sus potencialidades y no en la comparación de esta técnica con otras.

El objetivo es continuar el trabajo en el campo periodontal, con los diferentes instrumentos que tenemos, gracias a la biotecnología, para obtener la regeneración total de tejidos periodontales perdidos, con el fin de recrear de manera predecible y reproducible una anatomía periodontal real.

\section{BIBLIOGRAFÍA}

1. Zeichner-David M. Regeneration of periodontal tissues: cementogenesis revisited. Periodontol 2000 2006;41: 196-217.

2. Needleman I, Tucker R, Giedrys-Leeper E, Worthington $H$. Guided tissue regeneration for periodontal intrabony defects - a Cochrane Systematic Review. Periodontol 2000 2005;37:106-23.

3. Saygin NE, Giannobile WV, Somerman MJ. Molecular and cell biology of Cementum. Periodontol 2000 2000;24:73-98.

4. Bartold PM, Shi S, Gronthos S. Stem cells and periodontal regeneration. Periodontol 2000 2006;40:164-72.

5. Friedenstain AJ, Gorskaja JF, Kulagina NN. Fibroblastic precursors in normal and irradiated mouse hematopoietic organs. Exp Hematol 1976;4(5):267-74.

6. Gronthos S, Graves SE, Ohta S, Simmons PJ. The STRO$1+$ fraction of adult human bone marrow contains the osteogenic precursors. Blood 1994;84(12):4164-73.

7. Gronthos S, Zannettino AC, Hay SJ, Shi S, Graves SE, Kortesidis A, Simmons PJ. Molecular and cellular characterisation of highly purified stromal stem cells derived from human bone marrow. J Cell Sci 2003;116(Pt 9):1827-35.

8. D'Errico JA, Ouyang H, Berry JE et al. Immortalized cementoblasts and periodontal ligament cells in culture. Bone 1999;25:39-47.

9. Krebsbach PH, Robey PG. Dental and skeletal stem cells: potential cellular therapeutics for craniofacial regeneration. J Dent Educ 2002 Jun;66(6):766-73.

10. Hasegawa N, Kawaguchi H, Hiraci A, Takeda K, Mizuno N, Nishimura M, Koike C, Tsuji K, Iba H, Kato Y, Kurihara $\mathrm{H}$. Behavior of transplanted bone marrow-derived mesenchimal stem cells in periodontal defects. J Periodontol 2006 Jun;77(6):1003-7.

11. Song AM, Shu R, Xie YF, Song ZC, Li HY, Liu XF, Zhang XL. A study of enamel matrix proteins on differentiation of 
porcine bone marrow stromal cells into cementoblasts. Cell Prolif 2007 Jun;40(3):381-96.

12. Zhao Q, Gong P, Tan Z, Tang X. Differentiation control of transplanted mesenchimal stem cells (MSCs): a new possible strategy to promote periodontal regeneration. Med Hypotheses 2008;70(5):944-7.

13. Seo BM, Miura M, Gronthos S, Bartold PM, Batouli S, Brahim J, Young M, Robey PG, Wang CY, Shi S. Investigation of multipotent postnatal stem cells from human periodontal ligament. Lancet. 2004 Jul 1016;364(9429):149-55.

14. Gay IC, Chen S, MacDougall M: Isolation and characterization of multipotent human periodontal ligament stem cells. Orthod Craniofacial Res. 2007;10: 149-60.

15. Jo YY, Lee HJ, Kook SY, Choung HW, Park JY, Chung JH, Choung YH, Kim ES, Yang HC, Choung PH. Isolation and characterization of postnatal stem cells from human denal tissue. Tissue Eng 2007 Apr;13(4):767-73.

16. Trubiani O, Orsini G, Caputi S, Piattelli A. Adult mesenchymal stem cells in dental research: a new approach for tissue engineering. Int J Immunopathol Pharmacol. 2006 Jul-Sep; 19(3):451-60.

17. Fujii S, Maeda H, Wada N, Tomokiyo A, Saito M, Akamine A. Investigating a clonal human periodontal ligament progenitor/stem cell line in vitro and in vivo. J Cell Physiol. 2008 Jun;215(3):743-9.

18. Bartold PM, XiaoY, Lyngstaadas SP, Paine ML, Snead ML. Principles and applications of cell delivery systems for periodontal regeneration. Periodontol 2000 2006;40: 123-35.

19. Tomokiyo A, Maeda H, Fujii S, Wada N, Shima K, Akamine A. Development of a multipotent clonal human periodontal ligament cell line. Differentiation. 2008;Apr;76 (4):337-47.

20. Bhatia R. et al. Mesenchymal stem cells: future source for reparative medicine. Congest Heart Fail 2005; 11 (2): 87-91.

21. Pittenger MF, Mackay AM, Beck SC, Jaiswal RK, Douglas R, Mosca JD, Moorman MA, Simonetti DW, Craig S, Marshak DR. Multilineage potential of adult human mesenchymal stem cells. Science. 1999 Apr 2;284(541 1): 143-7.
22. Kawaguchi H, Hirachi A, Hasegawa N, Iwata T, Hamaguchi H, Shiba H, Takata T, Kato Y, Kurihara H.. Enhancement of periodontal tissue regeneration by transplantation of bone marrow mesenchymal stem cells. J Periodontol. 2004 Sep;75(9):1281-7.

23. Caplan A. I. Review: Mesenchymal stem cells: cell-based reconstructive therapy in Ortopedics. Tissue eng. 2005 Jul-Aug; 11 (7-8): 1 198-211.

24. Salvadè A, Bellotti D, Donzelli E, D’Amico G, Gaipa G, Renoldi G, Carini F, Baldoni M, Pogliani EM, Tredici G, Biondi A, Biagi E. GMP-grade preparation of biomimetic scaffolds with osteo-differentiated autologous mesenchymal astromal cells for the treatment of alveolar bone resorption in periodontal disease. Cytotherapy 2007;9(5):427-38.

25. Donzelli E, Salvadè A, Mimo P, Viganò M, Morrone $M$, Papagna R, Carini F, Zaopo A, Miloso M, Baldoni M, Tredici G. Mesenchymal stem cells coltured on a collagen scaffold: In vitro osteogenic differentiation. Arch Oral Biol 2007;52:64-73.

26. Anselme K, Bacques C, Charriere G, Hartmann DJ, Herbage D, Garrone R.. Tissue reaction to subcutaneous implantation of collagensponge. A histological, ultrastructural and immunological study. J Biomed Mater Res. 1990 Jun;24(6): 689-703.

27. Stahl SS. Froum SJ. Kushner J. Healing response of human intraosseous lesions following the use of debridement, grafting and citric acid root treatment. II. Clinical and histologic observations one year post surgery. J Periodontol 1983;54: 325-8.

28. Yukna RA. Mellonig JT. Histologic evaluation of periodontal healing in humans following regenerative therapy with enamel matrix derivative. A 10-case series. J Periodontol 2000;71:752-9.

29. Bowers GM, Chadroff B, Carnevale R, Mellonig J, Corio R, Emerson J, Stevens M, Romberg E. Histologic evaluation of new attachment apparatus formation in humans. Part II. J Periodontol 1989;60:675-82.

30. Kornman KS, Robertson PB. Fundamental principles affecting the outcomes of therapy forosseous lesions. Periodontol 20002000 Feb;22:22-43

31. Kalpidis CD, Ruben MP. Treatment of intrabony periodontal defects with enamel matrix derivative: a literature review. J Periodontol 2002 Nov;73:1360-76. 
32. Pontoriero R, LindheJ. Guided tissue regeneration in the treatment of degree III furcation defects in maxillary molars. J Clin Periodontol 1995;22:810-2.

33. Pountos I, Giannoudis PV. Biology of mesenchymal stem cells. Injury 2005 Nov;36 Suppl 3:S8-S12.

34. Goel A, Sangwan SS, Siwach RC, Ali AM. Percutaneous bone marrow grafting for the treatment of tibial nonunion. Injury 2005 Jan;36(1):203-6.

35. Quarto R, Mastrogiacomo M, Cancedda R, Kutepov SM, Mukhachev V, Lavroukov A, Kon E, Marcacci M. Repair of large bone defects with the use of autologous bone marrow stromal cells. N Engl J Med 2001 Feb;344(5): 385-6.

\section{CORRESPONDENCIA}

Dr. Giovanni Battista Menchini Fabris a/c Clínica Odontológica Villa Serena Hospital San Gerardo

Via Pergolesi, 17

Monza. Italia

email: gbmenchinifabris@med.unipi.it 